www.jmscr.igmpublication.org

Impact Factor (SJIF): 6.379

Index Copernicus Value: 71.58

ISSN (e)-2347-176x ISSN (p) 2455-0450

crossref DOI:_https://dx.doi.org/10.18535/jmscr/v6i4.57

Journal Of Medical Science And Clinical Research

\title{
A Comparative Analysis of Results of Suspensory Femoral Fixation and Interference Screw Femoral Fixation in Arthroscopic Anatomical Anterior Cruciate Ligament Reconstruction with Quadruple Hamstring Graft
}

\author{
Authors \\ Dr Rahul Mandal ${ }^{1}$, Dr Atul Uttamrao Tat ${ }^{2}$ \\ ${ }^{1}$ RMO-CT (Tutor), Dept. of Orthopaedics, Medical College, Kolkata \\ ${ }^{2}$ Associate consultant, Revival Bone \& Joint hospital \\ Corresponding Author \\ Dr Rahul Mandal \\ Email: rm6668@gmail.com
}

\begin{abstract}
Background: Arthroscopic anterior cruciate ligament reconstruction is the most commonly performed arthroscopic procedure performed worldwide.

Material and Methods: Patients operated between January 2013 to February 2014were included in study.

Result: Out of 44 patients 4 were lost to follow up. Eventually our sample size became 40 out of which Interference Screw group comprised of 20 patients and Suspensory Fixation group comprised of 20 patients.

Conclusion: All of our patients reported satisfactory outcomes regardless the procedure adopted. Younger age group and non-meniscal injury group shows better outcome.

Keywords: Arthroscopy, ACL.
\end{abstract}

\section{Introduction}

Anterior cruciate ligament (ACL) rupture is one of the most common knee injuries in sports. The treatment options for an ACL tear include non operative treatment, repair of the ligament (isolated or with augmentation) \&reconstruction with auto graft, allograft or synthetic materials ${ }^{1}$. Reconstruction of the ACL appears to be a better modality of treatment than repair considering the high failure rates of the latter ${ }^{1}$. The goal of ACL reconstruction is to reproduce the functions of the native ACL. Over the past three decades, clinically relevant biomechanical studies have provided us with important data on the ACL, particularly on its complex anatomy and functions in stabilizing the knee joint in multiple degrees of freedom ${ }^{2}$. The timing of ACL reconstruction after trauma is important. Delaying the procedure till the inflammation resolves and full range of motion of the knee returns aids in reducing post operative stiffness ${ }^{3}$. Preoperative criteria of the knee to yield successful results to ACL reconstruction are minimal or no effusion, good leg control, full range of knee motion, including full hyperextension ${ }^{4}$.In the past, extra-articular procedures were developed which involved 
tenodesis of the iliotibial band with or without bicepsplasty. This led to the development of intraarticular procedures ${ }^{1}$ which may be done arthroscopically or via a mini-arthrotomy incision. Arthroscopic reconstruction is preferred over open techniques due to faster rehabilitation, minimal access nature and better patient compliance. For successful ACL reconstruction four basic things are required, those are: Graft selection, Graft placement, Graft tensioning and Graft fixation ${ }^{5}$. In this study we used quadruple hamstring graft ${ }^{6,7.8 .9}$ placing it in anatomical position with transportal technique. Femoral fixation of the graft can be done by multiple types. In this study suspensory fixation was compared with the interference screw fixation.

\section{Material and Methods}

This study was conducted in department of orthopaedics in R G Kar Medical College \& Hospital, Kolkata. Patients operated between January 2013 to February 2014 were included in the study. A total of 44 patients satisfied the inclusion criteria. The inclusion criterion were all patients having ACL injury with or without meniscal injury. Exclusion criteria were patients with associated PCL injury, patients with periarticular knee fracture, patients with more than grade 2 medial or lateral laxity.

\section{Pre Operative Planning}

In our study patients were between 20 to 40 years of age having complaints of giving away sensation of a knee, were thoroughly examined and investigated. Injuries to the ACL were demonstrated clinically by the instability tests like Anterior Drawer test ${ }^{10,11,12}$, Lachman test ${ }^{13}$ and Pivot shift test ${ }^{14}$. Presence of meniscal injuries in the affected knee were tested by standard tests like joint line tenderness, Apley's grinding test and Mc Murray test. PCL injury was ruled out by negative Posterior Drawer test and Quadriceps Active test. Patients with clinically proven ACL injury, with or without meniscal injury were subjected to radiographic examination. Plain X-rays of the knees (AP and lateral) views were taken and MRI of the affected knee obtained.

\section{Operative Procedure}

Graft harvest and preparation: We used quadrupled hamstring tendon in all the cases. Semitendinosus tendon with or without Gracilis tendon were harvested through a vertical incision made 3 finger breadths below the medial joint line. Femoral end of the graft was marked at $1 / 3^{\text {rd }}$ of measured graft size.

Tunnel placement: a) Femoral Tunnel: The area around the lateral wall was cleared of all the fibrous tissue to visualize properly. The femoral tunnel centered $5 \mathrm{~mm}$ anterior to the posterior capsular insertion on the lateral femoral condyle at or just posterior o resident ridge. This was checked arthroscopically to be at the 10 o'clock position on the clock face in the right knee (2 o'clock in the left knee). A bone awl, inserted through the accessory anteromedial portal into the center of the femoral tunnel site, which indicated the position of the proposed femur tunnel. After the femoral tunnel had been confirmed, the knee was fully flexed 120 degree and a 2.4-mm Beath pin was introduced through the accessory anteromedial portal. Then a bicortical femoral tunnel was drilled using a $4.5-\mathrm{mm}$ drill. The femoral tunnel was then reamed to a $20-30 \mathrm{~mm}$ depth using a cannulated femoral stepped reamer according to the size of the graft (minimum diameter7 $\mathrm{mm}$ ). The tunnel is reamed in exactly the thickness of the graft e.g. if graft is of $8 \mathrm{~mm}$, tunnel is reamed with $8 \mathrm{~mm}$ reamer. SS wire was passed through this tunnel. b) Tibial Tunnel: At 90 degree of knee flexion the tibial tunnel is made. An elbow-aiming ACL tibial guide was placed through the medial portal at the native footprint of the ACL $7 \mathrm{~mm}$ anterior to PCL. A Beath pin was then introduced into the joint. Tibial tunnel was then drilled using the tibial stepped reamer. The tibial tunnel was drilled at the same diameter as the graft diameter.

Passage of Graft: The SS wire was then passed through the tibial tunnel and the graft was passed from tibial tunnel towards the femoral tunnel. 
Femoral Fixation: Femoral fixation of the graft was done using interference screw or endobutton rigidloop depending upon the type of fixation planned in the particular case. The knee was then put through a range of motion and the graft was checked to ensure that it did not impinge ${ }^{15,16,17}$ on the notch allowing hyperextension of knee. In loop fixation, we measured the length of the mercilene tape by deducting femoral graft length from whole femoral tunnel length $\&$ adding $5 \mathrm{~mm}$ for play. Then mercilene tape is passed within the endobutton \& graft is passed through SS wire. Then endobutton is locked over the lateral femoral cortex.

Graft tensioning and tibial fixation: After femoral fixation graft was tensioned through the tibial tunnel. After that repeated cycling loading of the knee was done. Maintaining the traction, guide wire was inserted in tibial tunnel followed by screw. The screw was inserted $5-10 \mathrm{~mm}$ inside the tunnel so that it did not come out when the screw driver was removed.

The knee was put through a full range of motion and restoration of stability was confirmed. The joint was irrigated and suctioned of any remaining debris. Final position and tension of the graft checked arthroscopically.

Patients were followed up at 4 weeks, 3 months \& 6 months after surgery. IKDC SCORES in pre and post operative period were noted.

\section{Post Operative protocol: ACL} rehabilitation ${ }^{18,19,20}$ protocol followed and suture removal done after 2 weeks.

\section{Results}

A total of 44 patients satisfied the inclusion criteria and underwent the study; however 4 patients were lost to follow up. Eventually our sample size available for evaluation was of 40 patients. The INTERFERENCE SCREW group comprised of 20 patients and the SUSPENSORY FIXATION (ENDOBUTTON) group comprised of 20 patients.

There were no intra-operative or post-operative complications apart from occasional pain and headache, which were managed accordingly.

Follow up evaluation was done at intervals of 1 month (4 weeks), 3 months and 6 months.

Table 1: IKDC Score in MI /NMI Patients Undergoing IFS Fixation

\begin{tabular}{|c|c|c|c|c|c|c|c|c|c|}
\hline \multirow[t]{2}{*}{$\begin{array}{l}\text { Meniscal } \\
\text { Injury }\end{array}$} & \multirow[t]{2}{*}{$\begin{array}{c}\text { No. of } \\
\text { Patients }\end{array}$} & \multirow[t]{2}{*}{$\begin{array}{c}\text { Percen- } \\
\text { tage }\end{array}$} & \multirow{2}{*}{$\begin{array}{c}\text { Pre- } \\
\text { operative } \\
\text { Mean score }\end{array}$} & \multicolumn{2}{|c|}{$\begin{array}{l}\text { At } 4 \text { (Four) } \\
\text { weeks }\end{array}$} & \multicolumn{2}{|c|}{$\begin{array}{c}\text { At } 3 \text { (Three) } \\
\text { months }\end{array}$} & \multicolumn{2}{|c|}{$\begin{array}{c}\text { At } 6 \text { (Six) } \\
\text { months }\end{array}$} \\
\hline & & & & Score & Diff. & Score & Diff. & Score & Diff. \\
\hline MI & 8 & $40 \%$ & 48.63 & 71.88 & 23.25 & 84.13 & 35.50 & 94.00 & 45.37 \\
\hline NMI & 12 & $60 \%$ & 46.92 & 70.00 & 23.08 & 82.00 & 35.08 & 93.92 & 47.00 \\
\hline
\end{tabular}

$\mathrm{t}=-0.52, \mathrm{df}=18, \mathrm{p}=0.304$ (not significant)

Table 2: IKDC Score in MI/NMI Patients Undergoing Endobutton Fixation

\begin{tabular}{|c|c|c|c|c|c|c|c|c|c|}
\hline \multirow[t]{2}{*}{$\begin{array}{l}\text { Meniscal } \\
\text { Injury }\end{array}$} & \multirow[t]{2}{*}{$\begin{array}{l}\text { No. of } \\
\text { Patients }\end{array}$} & \multirow[t]{2}{*}{$\begin{array}{l}\text { Percen- } \\
\text { tage }\end{array}$} & \multirow{2}{*}{$\begin{array}{c}\text { Pre- } \\
\text { operative } \\
\text { Mean score }\end{array}$} & \multicolumn{2}{|c|}{$\begin{array}{l}\text { At } 4 \text { (Four) } \\
\text { weeks }\end{array}$} & \multicolumn{2}{|c|}{$\begin{array}{c}\text { At } 3 \text { (Three) } \\
\text { months }\end{array}$} & \multicolumn{2}{|c|}{$\begin{array}{c}\text { At } 6 \text { (Six) } \\
\text { months }\end{array}$} \\
\hline & & & & Score & Diff. & Score & Diff. & Score & Diff. \\
\hline MI & 12 & $60 \%$ & 49.67 & 69.83 & 20.16 & 82.08 & 32.41 & 90.50 & 40.83 \\
\hline NMI & 8 & $40 \%$ & 45.88 & 70.13 & 24.25 & 81.00 & 35.12 & 90.50 & 44.62 \\
\hline
\end{tabular}

$\mathrm{t}=-1.57, \mathrm{df}=18, \mathrm{p}=0.066$ (not significant)

\section{Discussion}

We studied total 30 males and 10 females. In our study the mean age of patients was 30.80 years with $\mathrm{SD}=4.53$, the youngest being 23years and eldest being 40 years which corresponds the age group of the ACL injury which is more common in young and active adults. The results of the IFS group were better overall but age wise but there is no statistical difference. The mean improvement in IKDC score for IFS group was 46.35. The mean preoperative IKDC score for IFS group was 47.60 which rose to 93.95 after 6 months of intervention. While the mean improvement of IKDC score in ENDO group was 42.35 . The mean preoperative IKDC score for ENDO group was 48.15, which increased to 90.5 at 6 months after the operation. 
The difference in the IKDC score at 6 months after intervention was statistically significant $(\mathrm{P}=0.023)(\mathrm{t}=2.05$.

Our study comprised of the total 30 males and 10 females. The mean preoperative IKDC score for males was 47.50 rising to 91.97 and for females it was 49 increasing to 93 at 6months.

IFS group consisted of 13 males and 7 females. Improvement in IKDC score was better for males as compared females with difference of 47 for males and 45.14 for females after 6 months. The mean preoperative IKDC score for males was 46.92 which rose to 93.92 and for females it was 48.86 increasing to 94 at 6 months of follow up. The final IKDC score was better for males but it was not statistically significant $(\mathrm{P}=0.287)$ $(\mathrm{T}=0.57)$.

In ENDO group 17 were males and 3 were females. The mean preoperative IKDC score for males was 47.94 rising to 90.47 and that for females was 49.33 increasing to 90.67 at 6 months after intervention. Though the improvement for males was slightly better, it was not statistically significant $(\mathrm{P}=0.368)(\mathrm{T}=0.34)$.

With respect to meniscal injury the increase in IKDC score was 42.65 for those who had MI as compared to 46.05 of NMI. The mean preoperative IKDC score for MI patients was 49.25 which rose to 91.90 and for NMI patients it was 46.50 increasing to 92.55 at 6 months of follow up. The improvement in IKDC score was better for NMI patients as compared to MI patients and it was statistically significant with $\mathrm{P}=0.046(\mathrm{~T}=-1.72)$.

Of all the patients operated post operative knee laxity not found in any of the patients of both the groups. In most of our cases, we used interference bio screw which is slightly costlier than endobutton. While titanium screws expenditure was similar to endobutton. The average expenditure for the IFS group was 16 thousand rupees and for ENDO group it was 12 thousand rupees, IFS being slightly costlier than ENDO. The average operating time was 70 minutes which was ranging from 60 minutes to 80 minutes. With average operating time being same for both IFS \& ENDO group there was no significant difference in operating time for both procedures. Revision surgery was not required in any of our patients during the follow up.

\section{Conclusion}

A total of 40 patients available for follow up. There were no significant complications except for infection in one patient which was managed conservatively with oral antimicrobial agents. Results were recorded by IKDC score at intervals of 4 weeks, 3 months and 6 months post operatively. All of our patients reported satisfactory outcomes regardless of the procedure adopted. Younger age correlated with better outcome in both type of fixation with interference screw fixation better than endobutton fixation. Patients with MI had poorer outcome than NMI patients while gender had no bearing on results. Both the procedures were found to be safe and reliable in producing the desired results. Our study was limited in aspects like small sample size, short duration of follow up and variable patient characteristics. Keeping these in mind we conclude that both IFS \& ENDO offer satisfactory outcome for femoral fixation in ACL reconstruction however results tilt in favour of IFS.

\section{References}

1. Campbell's operative orthopaedics, 12th edition, vol 3, page 2137-2138.

2. Insall And Scott: surgery of knee, 4th edition, vol-1, page-228.

3. Insall and scott: surgery of knee, 4th edition, vol-1, page633.

4. Shelbourne KD, Patel DV. Timing of surgery in anterior Cruciate ligament injured knees. Knee surgtraumatol arthrosc3:148, 1995.

5. Campbell's operative orthopaedics, 12th edition, vol 3, page 2142.

6. Galeazzi R. La recostituzionedeiligamenticrociati del ginocchio. Atti e 
Memorie della Societalombarda di Chirurgica 1934;13:302-317.

7. Macey HB. A new operative procedure for the repair of ruptured cruciate ligament of the knee joint. Surg Gynecol Obstet. 1939;69:108-109.

8. Cho KO. Reconstruction of the anterior cruciate ligament by semitendinosus tenodesis. J Bone Joint Surg Br. 1975;57A:608-612.

9. Puddu JC. Method for reconstruction of the anterior cruciate ligament using semitendinosus tendon.Am J Sports Med. 1980;8(6):402-404. doi: 10.1177/036354658000800603.

10. O'Donoghue DH. Reconstruction for medial instability of the knee: techniques and results in sixty cases.J Bone Joint Surg Br. 1973;55-A:941-954.

11. Nicholas JA. The five one reconstruction for antero medial instability of the knee. J Bone Joint Surg Br.1973;55-A:899-922

12. Hughston JC, Eilers AF. The role of the posterior oblique ligament in repairs of acute medial ligament tear of the knee. J Bone Joint Surg Br. 1973;55(5):923-940.

13. Torg JS, Conrad W, Kalen V. Clinical diagnosis of anterior cruciate ligament instability in athlete. Am J Sports Med. 1976;4:84-93. doi: 10.1177/036354657600400206.

14. Galway R, Beaupré A, mac Intosh DL. A clinical sign of symptomatic cruciate insufficiency. J Bone Joint Surg Br. 1973;54-B:763-764.

15. Good L, Odensten M, Gillquist J.

Intercondylar notch measurements with special reference to anterior Cruciate ligament surgery .clin orthop263:185, 1991.

16. Munetat, Takakuda $\mathrm{K}$, yamamoto $\mathrm{H}$ : Intercondylar notch width and its relation to the configuration and cross sectional area of the anterior Cruciate ligament. Am J Sports Med25: 69, 1997.

17. Duthon VB, Barea C, Abrassart S, Fasel JH, Fritschy D, Menetrey J. Anatomy of the anterior cruciate ligament. Knee Surg Sports Traumatol Arthrosc. 2006;14:204213. doi: 10.1007/s00167-005-0679-9.

18. Beynnon BB, Fleming BC, Johnson RJ et al. Anterior Cruciate ligament strain behaviour during rehabilitation exercises in vivo. Am J Sports Med 1995; 23:24.

19. Beynnon BB, Fleming BC, Johnson RJ et al. The strain behaviour of anterior Cruciate ligament : a comparison of open and closed chain kinetic exercise. Am J Sports Med 1997;25:823.

20. Beynnon BD, Pope MH, Wertheimer CM, et al: The effect of functional knee-braces on strain on the anterior cruciate ligament in vivo. $\mathrm{J}$ Bone Joint Surg 1992; 74A:1298. 